\title{
Letters
}

Website: bmj.com

Email: letters@bmj.com

\section{Cheating at medical school}

Editorial p 250 and Papers p 274

\section{Anonymous letter should have been consigned to the bin}

EDITOR-I was disappointed to read Smith's editorial on cheating at medical school. ${ }^{1}$ Trial by media has become a sign of the times, but I had hoped that the professional journal of the medical profession would rise above such sensationalism. It is easy for us all to be filled with righteous indignation about the cheating of a student, but we do not know all the circumstances, and I hope that adherence to confidentiality means that we never will.

The appropriate authority dealt with the issue, and I believe that it is nobody else's business. What right has the media to question a judgment based on facts when they do not have all the facts at their disposal? In any event, I wonder about the motives of the student who exposed this lapse by one of his or her colleagues anonymously.

Of course doctors must have integrity, but it is wrong to assume that a person lacks integrity on the basis of one incident. After all, who can affirm that they have never once been dishonest in their entire career? Hopefully, we learn from our mistakes and aim to do better in the future.

\section{Advice to authors \\ We prefer to receive all responses electronically, sent either directly to our website or to the editorial office as email or on a disk. Processing your letter will be delayed unless it arrives in an electronic form. \\ We are now posting all direct submissions to our website within 24 hours of receipt and our intention is to post all other electronic submissions there as well. All responses will be eligible for publication in the paper journal. \\ Responses should be under 400 words and relate to articles published in the preceding month. They should include $\leqslant 5$ references, in the Vancouver style, including one to the BMJ article to which they relate. We welcome illustrations. \\ Please supply each author's current appointment and full address, and a phone or fax number or email address for the corresponding author. We ask authors to declare any competing interest. Please send a stamped addressed envelope if you would like to know whether your letter has been accepted or rejected. \\ Letters will be edited and may be shortened. \\ bmj.com \\ letters@bmj.com}

Smith says that justice is not a private matter and calls for exposure. I think that exposure has little to do with justice and much more to do with selling newspapers. Public opinion is more influenced by the media slant or spin than the facts of the case. How often do tabloid newspapers treat us to full exposure of the life of person who has been accused of a crime well before any trial has taken place? Where is the justice in that? We are in serious danger of engendering a situation in which the fear of publicity is such that decisions made by responsible people will be expedient rather than just.

I think that the $B M J$ should have consigned this anonymous letter to the waste paper basket and not taken the opportunity to call into question the integrity of a future member of the medical profession. This editorial does little to support a beleaguered profession and could cause much more serious damage.

\section{S A Spencer senior lecturer in paediatrics, Keele} University

North Staffordshire Hospital, Stoke on Trent ST4 6QG

andy_spencer@hotmail.com

1 Smith R. Cheating at medical school. BMJ 2000;321:398. (12 August.)

\section{Incident was dealt with appropriately}

EDITOR-I was disturbed by Smith's editorial on cheating at medical school. ${ }^{1}$ In the current climate of doctor bashing by the media and the recent vigilante attacks on supposed paedophiles and mob violence in the name of justice, I was disappointed that Smith thought that doctors should respond to this student's cheating in a way that would show other students and the public that justice had been done. Rather than undermine faith in our system of justice I think that we should be highlighting that this matter was dealt with appropriately.

Smith's editorial was based on information in an anonymous letter, whose writer must have led a protected life if this is the most ugly scene that he or she had witnessed. If this was such a significant event surely he or she could have signed the letter? I note that Smith confirmed the facts with the medical school concerned, but owing to confidentiality I am sure that he was not given all the details.

We all know how stressful medical final examinations can be, the culmination of five or six years of striving to be a doctor.
Depression, anxiety, and stress often unhinge previously stable minds. The student in this case had been exemplary before this event. I agree that cheating destroys trust and the incident must be dealt with professionally and fairly, but must we respond to a lynch mob mentality in order that justice is seen to be done? I think that the medical school probably responded in a measured way. Rather than lose a valuably trained doctor we have gained a professional who has learnt a painful lesson.

Belinda Brewer general practitioner registrar Wittering's Health Centre, East Wittering, West Sussex PO20 8BH

binksbrewer@hotmail.com

1 Smith R. Cheating at medical school. BMJ 2000;321:398. (12 August.)

\section{Public horsewhipping is not the answer}

EDITOR-I read with dismay the aspersions cast at one of my colleagues and my medical school by Smith in his editorial on cheating.

This matter was indeed public knowledge within a very short time. The fact that it was not deliberately publicised does not, I believe, signify an intention to cover it up. Such disciplinary matters must be commonplace in any school and are dealt with in private with all the facts present-as they should be. Who ever heard of a disciplinary board that worked like "America's Funniest Home Videos," inviting the public to "press a button now" to decide the outcome? Which medical school can say that it has never had to deal with cheating before?

University College London Medical School has an excellent reputation in the United Kingdom and abroad, and its exams are rigorous. Such a matter should not call into question the validity of its degrees or the integrity of its tutors. Surely name calling is not necessary? As to the call for debate? By all means, but please keep everything in perspective.

It is in itself unethical and unnecessary to wilfully scupper the career of a young doctor if there is any way to prevent it. The doctor in this case has not killed or poisoned anyone, unlike some of our ilk. She has cheated, a crime, and she should be punished. By all accounts, she was let off lightly, but what would a public horse whipping do? It would destroy her both emotionally and professionally. The public's appetite for blood would be sated, but at what price? How could we as human beings forgive ourselves if she were to sink into depression and harm herself-for that may be the only way to go. We would have closed off all her avenues before her career has begun. Justice 
involves punishment, but after punishment must come rehabilitation and reintegration into the fold.

The people who need to know about her transgression no doubt already know. They must now be responsible for guiding her in the difficult times she has brought on herself. If she is repentant and able to do so, she must get on with life and become a good doctor-one to be proud of.

Emile Tan final year student

University College London Medical School,

London WC1E 6BT

emile.tan@virgin.ne

1 Smith R. Cheating at medical school. BMJ 2000;321:398 (12 August.)

\section{Cheating should be treated like medical error}

EDITOR-The responses to the theme issue on medical error were published a week after Smith's editorial about a final year student caught cheating at medical school. ${ }^{2}$

Is there not a parallel here? Should we not only be looking at the person who cheated but also be finding out why it happened and how it can be avoided? Should we not stop upholding the supposed integrity of the profession by proudly expelling the miscreant according to the name and shame culture the $B M J$ was so critical of?

Chris O'Loughlin senior house officer in psychiatry Friends Ward (Box 309), Addenbrooke's Hospital, Cambridge CB2 2QQ

c.oloughlin@btinternet.com

1 Smith R. Cheating at medical school. BMJ 2000;321:398. (12 August.)

2 Correspondence. Reducing error, improving safety. $B M$ J 2000;321:505-9. (19-26 August.)

\section{Committee should be commended for} showing compassion

EDITOR-I enjoyed reading Smith's editorial about the hapless finals cheat and anonymous whistleblower-but only in the way that I enjoy reading the tabloid newspapers on vicars being caught in flagrante delicto with one of their parishioners.

I am surprised that someone caught cheating in an examination is allowed to pass, and this outcome was probably a bitter pill to swallow for the unfortunate students who failed their finals without the peroperative assistance of the Oxford Clinical Handbook. However, two possible interpretations of the editorial are that anyone caught cheating in an examination is not fit to practise as a doctor and that justice can be dispensed only if the perpetrator of any deceitful act is publicly exposed and humiliated.

I may be wrong in disagreeing with the first contention that anyone caught cheating in an examination is not fit to practise, but I believe that in a compassionate and supposedly Christian society public exposure and humiliation is utterly contemptible. The anonymous whistleblower would certainly not have written to the $B M J$ if the cheat had been summarily dismissed from medical school with no hope of ever reaping the benefits of five or six years' hard work (I assume that even cheats have to work hard to get through medical school). The whistleblower's spiteful desire to see the cheat receive her comeuppance would have been fulfilled. $\mathrm{He}$ or she did not have the courage to put a name to these demands for a harsher penalty, and we can only guess at the true motives behind them (jealousy of the prizes of which the cheat has been stripped?).

The cheat has cheated no one but herself. I would be most surprised if her foolish use of the Oxford Clinical Handbook will have had any significant effect on the outcome of her examination, which is clearly what the disciplinary committee thought The committee decided to treat her with compassion, something that is sadly lacking in the unpleasant world in which today's doctors practise. I think that the committee should be commended for showing compassion and not made to feel that it has somehow aided and abetted a mythical decline in the moral standards of the medical profession.

William Westlake research fellow

McCusker Glaucoma Unit, Lions Eye Institute, Nedlands 6009, Western Australia westlake@networx.net.au

\section{Smith R. Cheating at medical school. BMJ 2000;321:398 (12 August.)}

\section{Examination committee's decision tarnishes reputations}

EDITOR-The $B M J$ was right in helping to expose the astonishing episode of unpunished cheating during a final examination at the Royal Free and University College London Medical School. ${ }^{1}$ If the student who cheated was passed by the examination committee because she had previously been an exemplary student (and now there will forever be doubt on the veracity of this description of her), then what is the point of the examination if exemplary students will be passed even if they have cheated? Perhaps robust continuous assessment of course work would be a better alternative for all candidates and could still identify students worthy of distinctions and prizes.

Exemplary students have failed for various mitigating reasons throughout the history of examinations. Many have swallowed the bitter pill and tried again, often with salutiferous effects. This is the first example I know of a cheat being passed when she should have failed. Not only was she dishonest (at least once) but she clearly had an illicit and unfair advantage over other candidates sitting the same examination. In undermining the whole process, the examination committee has failed all graduates of this medical school. A question mark must now hang over all graduate results from this medical school if confidence is lost with the examination committee, as now seems likely. If the cheat's identity remains anonymous, all recent female graduates from this particular school may be subconsciously or consciously viewed with suspicion at future job selections. This potential for discrimination is perhaps the greatest cause for concern among the honest female candidates who passed fairly.

The examination committee's extraordinary decision to pass a cheat needs an immediate full explanation (and perhaps an apology) if irreparable harm to the reputation of the Royal Free and University College London Medical School, its graduates, and the medical profession is to be minimised.

J Vive consultant radiologist

Surrey and Sussex healthcare NHS Trust, Crawley, West Sussex RH11 7DH

1 Smith R. Cheating at medical school. BMJ 2000;321:398. (12 August.)

\section{Cheating should be properly punished}

EDITOR-Smith in his editorial asks whether the $B M J$ was right to publicise the episode of cheating during a final examination at the Royal Free and University College London Medical School. ${ }^{1}$ I am surprised that he felt the need to ask-of course it was right.

The editorial raises two issues. The first is whether the student had attained the required standard without resorting to cheating. The examining committee obviously considered that she had but without proof (how often had she cheated in the past?). Surely the public needs to have confidence that all doctors have shown beyond doubt that they have the knowledge and ability to practise safe medicine? This has not happened in this case. I wonder what would have happened had this been an A level examination.

The second issue is the naivety of the committee in thinking that the medical profession wishes to adhere to old fashioned paternalism and allow a student to pass because she is known to be a good student. It is for just this reason that the General Medical Council has lost the confidence of the public. What happens now that the standards of academic achievement of the entire medical profession are to be questioned?

Smith is correct in saying that justice not only has to be done but also must be seen to be done. I am deeply upset that the student was not asked to resit the entire examination at the next sitting. I am grateful that some members of the profession are prepared to state publicly that the judgments made in this case are simply not good enough for a modern profession.

Neil Fergusson consultant anaesthetist Countess of Chester Hospital, Chester CH2 1BL Neil.Fergusson@btinternet.com

\section{Smith R. Cheating at medical school. BMJ 2000;321:398.} (12 August.)

\section{Keeping quiet about cheating will not increase public confidence}

EDITOR-Smith's editorial on cheating makes me more positive about the medical profession's future. ${ }^{1}$ We as doctors are not practising a secret craft any longer, and more openness and public discussion, although causing its own problems, is far to be preferred to mutterings about the secrets of our craft. After the Bristol affair, the Shipman case, and many others-particularly after evidence that responsible bodies 
ignored warnings and advice-keeping too quiet will not increase public confidence. The public will begin to ask what other skeletons are hidden in our cupboard.

Rod MacQueen staff specialist

Liverpool Hospital, Liverpool, New South Wales

2170, Australia

randjmac@ix.net.au

Smith R. Cheating at medical school. BMJ 2000;321:398. (12 August.)

Public declaration of an appropriate punishment is important

EDITOR-I support the $B M$ Js publication of the details of a student's cheating in her final examinations. ${ }^{1}$

Although professional knowledge and skills, which can be tested, are an important component of a doctor's work, I believe that the most important qualities in a doctor are honesty and integrity. Patients must be able to trust their doctors. In my experience, most patients will accept and understand when mistakes are honestly and openly explained.

When medical errors are publicised an important aspect of the criticism is the actual or perceived cover-up of the facts. Society is losing its trust in the integrity of the medical profession, and this is just as damaging as poor performance.

Although I have no personal knowledge of this case, I believe that the minimum appropriate punishment should have been to resit the examination. Important aspects of publicly declaring an appropriate punishment are to act as a deterrent to others; to highlight the importance of personal integrity; and to promote a culture of intolerance to dishonesty in the medical profession.

Michael Jarmulowicz consultant histopathologist Department of Histopathology, Royal Free Hospital, London NW3 2QG

mjarmulowicz@compuserve.com

1 Smith R. Cheating at medical school. BMJ 2000;321:398 (12 August.)

\section{Main impact of cheating is on clinical work}

EDITOR-Smith asks whether the $B M J$ has done the right thing to publicise an episode of cheating at medical school. ${ }^{1}$ Absolutely, and well done.

Early last year our department secretary told me that she thought that one of the final year undergraduates in our child health block had forged a consultant's signature to confirm completion of a compulsory component of the course. The forgery was crude and easy to detect; the student was confronted and admitted to doing it. The student failed the block as a direct consequence and will have to complete, satisfactorily, further "retraining" before proceeding to finals. It was made very clear that a similar action after qualification would be likely to result in referral to the General Medical Council.

Perhaps this student was just unlucky to have been caught: others had probably cheated before but not been discovered. However, at least we made a public response saying that we regarded it as cheating and unacceptable. All a bit depressing in a university medical school which widely and publicly states, throughout campus and on its website, that its first core value is the "habit of truth"

Smith rightly highlights the erosion and destruction of trust that follows cheating at medical school, but the main impact is not on the academic process or research but on daily clinical work. It would be almost impossible to function in a clinical team if you could not believe your other team members implicitly ("Have you really completed the consent form-or did you just forge it?"). And if you lie and cheat as a student, it is not likely to stop when you come up against the rigours of daily clinical practice. Just imagine, too, what might happen to the doctor in our bright new future who is caught forging his continuing professional development $\log$ in the GMC revalidation process.

Interestingly, the student in our department, like the one whose case was described by Smith, ${ }^{1}$ was another good student and was in line for a merit certificate. Perhaps all good students are cheats and liars.

James Paton senior lecturer in paediatric research Department of Child Health, Royal Hospital for Sick Children, Glasgow G3 8SJ

J.Y.Paton@clinmed.gla.ac.uk

1 Smith R. Cheating at medical school. BMJ 2000;321:398. (12 August.)

\section{Are we all cheats?}

EDITOR-It was manifestly wrong for the medical student to take the Oxford handbook into the examination. ${ }^{1}$ It is clearly wrong to seek to gain unfair advantage in an examination, whose rules and regulations are laid out. I would, however, be interested to know whether the former medical students who have been fulsome in their condemnation of this individual on bmj.com ${ }^{2}$ can claim to have never seen a multiple choice question from a past paper, received some hot tip for the written paper, or sought some knowledge of the cases in the clinical examinations from those who have just completed their assessments.

I feel confident in being able to guarantee that every medical school graduate in the past 20 years has transgressed in one of these ways, either as a student or as a doctor preparing for postgraduate examinations.

The board of examiners had to exercise wisdom. Their decision, as is to be expected, has not pleased everyone but was their prerogative. It was also Richard Smith's prerogative to air the issue in public. Is it too much to hope that the circumstances of this case can be used to move towards a more equitable examination system rather than the witch hunt that it seems to have become?

Are we all cheats?

Phillip Bennett-Richards general practitioner London E3 3HE

PhillipJBR@aol.com 1 Smith R. Cheating at medical school. BMJ 2000;321:398.
(12 August.)
2 Electronic responses. Cheating at medical school.
bmj.com;321 (www.bmj.com/cgi/content/full/321/7258 398\# responses; accessed 15 Jan 2001).
Cheating also happens on the large scale

EDITOR-As recent graduates from medical school, we would like to describe a recent case of cheating on a much larger scale than that described by Smith. ${ }^{1}$

Less than 12 hours before our first clinical examination we received a telephone call from a fellow finalist claiming to have a full list of the stations making up the objective structure clinical examination. Two students had seen the mark sheets when making inquiries at the examination office two days previously and had decided to disseminate the information.

What to do with the information proved to be difficult. Our consciences did not rest easy. Undoubtedly some candidates would have known the content of the examination for over two days and were confident of their sources' reliability. What also bothered us, however, was that many students would not have received a telephone call at all

The details we had received proved accurate. From conversations after the examination we learnt that many students had selectively revised and practised the subjects which they knew would be examined from the details they had received two days before (and the last 48 hours' work do make a difference).

Around half of the year was awarded a merit or distinction, awards that are given only to students gaining a merit in one of the two clinical examinations: the objective structure clinical examination and the long case. The number of merits and distinctions awarded this year was noticeably higher than in recent years.

As a result of this cheating many very able candidates who passed finals honestly will now seem to be less able on paper than some less able students who received the information. Undoubtedly, many less than average students had surprisingly good results after gaining merits in their objective structure clinical examination. Some students may have passed who would have failed had they not been privy to the examination details.

Will these dishonest people now be favoured for the best senior house officer jobs because they have good finals results? And will other equally if not more able students who were not informed of the examination details be penalised as a consequence? These are unanswerable questions.

Our consciences still struggle with this. We hope that the other 100 or so students involved also feel uncomfortable.

Cheating clearly happens at all levels and on all scales. We were all in the wrong, and perhaps we should have dealt with the problem differently. Should we now admit who we are and have our merits and distinctions and even honours awards taken away?

Smith R. Cheating at medical school. BMJ 2000;321:398. (12 August.) 


\section{Summary of rapid responses}

This editorial touched a nerve: responses came thick and fast. We posted 101 responses by 95 different respondents (or groups of respondents) from 10 August to 22 November, a fifth of them (21) on 15 August alone. ${ }^{1}$ Two thirds of responses (66) were posted during the first week of the editorial's availability on the web and nearly three quarters (74) during its first week of publication in the printed journal. We also received nine other letters by post.

Only four of the 85 respondents who gave their position were not medically qualified or in training. Forty four were specialists, 10 general practitioners, nine doctors working in academic institutions, seven medical students, six junior doctors, and three "doctors" or "medical practitioners," while two were retired. Most respondents (60) came from the United Kingdom, but seven were from Australia, six from the United States and Canada, three each from the Republic of Ireland, Europe, and India, two each from Hong Kong and South America, and one each from Malaysia, South Africa, and Japan.

Most respondents agreed that the editorial should have been published and thought that it raised important issues. The repercussions of cheating for the student and her peer group and on the medical profession as a whole were hotly debated, as well as the appropriateness of the punishment in this particular case. An important thread of the debate was whether the examination system should be changed to assess better the skills required of doctors in an age of information overload and increased patient awareness.

One of the most interesting threads, however, was the scale and extent of cheating at medical school. Five respondents asked to remain anonymous to blow the whistle on instances they had encountered. Nor is cheating new as this quote from the Daily Herald of 21 March 1938 shows:

Wholesale cheating has caused abandonment of a medical students' examination in London. The students, 150 of them, were taking a physiology paper set by the Conjoint Board. That cheating was going on was discovered only 15 minutes from the end of the examination. The supervising examiner grew suspicious when 20 students, one after another, asked permission to go to the cloakroom. Mr Horace New, secretary of the Conjoint Board, was asked to investigate. Behind a pipe in the cloakroom he found a "cram" book.

Might cheating at medical school remain endemic unless it is tackled openly? Sharon Davies letters editor, BMJ

1 Electronic responses. Cheating at medical school. bmj.com;321 (www.bmj.com/cgi/content/full/321/7258 398\#responses; accessed 15 Jan 2001).

\section{Drug treatment of multiple sclerosis}

\section{Clinical review was unsystematic}

EDITOR-Polman and Uitdehaag present a clinical review of drug treatment of multiple sclerosis that is unsystematic and makes no attempt to take account of existing systematic reviews of the evidence. ${ }^{1}$ In consequence, it has several important deficiencies as an assessment of the drugs available to help patients with this serious disease.

Firstly, the authors say that "the amount of [magnetic resonance imaging] lesions in the early phase of the disease predicts future disability" but make no comment about the conclusion of a recent meta-analysis of nine longitudinal studies that [gadolinium enhanced magnetic resonance imaging] "is not a strong predictor of the development ... of disability."

Secondly, they dismiss the older immunosuppressive drugs, saying that they have limited efficacy and considerable toxicity. They make no reference, however, to a recent systematic review of the randomised evidence about these drugs that puts them in context.

Thirdly, they include a short paragraph about the cost utility of interferon beta, with one single reference. A recent systematic review of relevant studies from across the world addressing this question found three looking at relapsing-remitting and two at secondary progressive disease. In each case the cost per quality adjusted life year was high, which raises the question of whether people with multiple sclerosis might derive more benefit from resources invested in services other than interferon beta. ${ }^{4}$

The assessment of health technologies requires an unbiased and systematic assessment of the totality of the available evidence. People with multiple sclerosis are not helped by incomplete reviews-neither are healthcare decision makers.

Ruairidh Milne senior lecturer in public health medicine

rm2@soton.ac.uk

Andy Clegg senior research fellow

Jackie Bryant research fellow

Wessex Institute for Health Research and

Development, Mailpoint 728, University of

Southampton, Southampton SO16 7PX

Competing interests: All the authors were authors of a recent rapid review of the effectiveness, costs, and utility of a range of disease modifying drugs in multiple sclerosis. They also work for the National Coordinating Centre for Health Technology Assessment, which manages the health technology assessment programme on behalf of the NHS.

1 Polman CH, Uitdehaag BMJ. Drug treatment of multiple sclerosis. BMJ 2000;321:490-4. (19-26 August.)

2 Kappos L, Moeri D, Radue EW, Schoetzau A, Schweikert K, Barkhof F, et al. Predictive value of gadolinium-enhanced magnetic resonance imaging for relapse rate and changes in disability or impairment in multiple sclerosis: meta-analysis. Lancet 1999;353:964-9.

3 Clegg A, Bryant J, Milne R. Disease-modifying drugs for multiple sclerosis: a rapid and systematic review. Health Technol Assess 2000:4:1-101.

Bryant J Clegr A, Milne R. Cost utility of drugs for mult ple sclerosis. Systematic review places study in context. BMJ 2000;320:1474-5. (27 May.)

\section{Authors' reply}

Editor-Milne et al argue that our clinical review of drug treatment of multiple sclerosis is unsystematic and of course it is. The $B M J$ invited us to write a review-using under 2000 words and no more than 30 references-that was accessible to informed general practitioners; it was explicitly stated that the methods were not expected to be systematic.

In addition to stating that our review was unsystematic Milne et al make three points. Their first one addresses magnetic resonance imaging, and it is obvious that they are confused by the characteristics of the different magnetic resonance variables. Some of the references given in our paper (especially 4, 5, and 25) address this aspect in detail. With regard to their second and third remarks we can conclude only that the messages from their papers do not challenge our statements that immunosuppressive drugs have not found widespread acceptance and that interferon beta has a high cost.

People with multiple sclerosis are not helped by letters to medical journals in which scientists refer only to their own papers without making relevant new points-neither are healthcare decision makers.

\section{H Polman professor}

B M J Uitdehaag neurologist

Department of Neurology, Academic Hospital Vrije Universiteit, PO Box 7057,1007 MB, Amsterdam,

Netherlands

ch.polman@azvu.nl

Competing interests: Both authors have received research grants and lecturing and consultancy fees from various pharmaceutical companies dealing with multiple sclerosis, including those that manufacture the various forms of interferon beta and glatiramer acetate.

\section{Declaration of Helsinki should be strengthened}

\section{Equipoise is essential principle of human experimentation}

EDitor-We wish to join in the debate about the next revision of the Declaration of Helsinki and to address some of the arguments put forward by Rothman et al.

We agree with Rothman and Michels that equipoise ("the uncertainty principle") is an essential ingredient of an ethical experiment and that the declaration should be amended to say so. We recently argued that extraordinary care should be given to understand and protect this fundamental principle, on which nearly the entire system of human experimentation stands.

Baum writes of "tensions between conduct of a trial and the autonomy of the individual." This involves the notion that patients who participate in trials are asked to make a sacrifice for the good of others. This concern, however, is alleviated by explicitly invoking equipoise as the principle on which randomised controlled trials are based. The uncertainty principle states that a patient should be enrolled in a randomised controlled trial only if uncertainty about which of the trial treatments would benefit the patient most is so substantial that they are in equipoise or "indifferent" between treatment options. ${ }^{45}$

It follows that so long as we are substantially uncertain which treatment is superior, patients do not lose out prospectively and are not required to sacrifice themselves for 
the benefit of others. ${ }^{4}$ Thus, ethically, randomised controlled trials should be acceptable to both utilitarians (who seek to bring the greatest good to the greatest number of patients by ensuring scientifically robust results) and Kantians (who seek to protect and preserve patients' autonomy). ${ }^{4}$ The same principle applies to any randomised trial, whether it is placebo controlled or not; it is just that in placebo controlled trials we should be particularly vigilant about applying the uncertainty principle. ${ }^{3}$

In our opinion, the ethical dilemma expressed in Rothman et al's article is false-it has already been resolved. The question is now a technical one: how do we improve communication so that patients can really find out whether or not they are indifferent between treatment options?

R J Lilford professor of research of public health and epidemiology

University of Birmingham, Birmingham B15 2TT helena.smith@doh.gsi.gov.uk

Benjamin Djulbegovic associate professor of oncology and medicine

H Lee Moffitt Cancer Centre and Research

Institute at the University of South Florida, Division of Blood and Bone Marrow Transplant, Tampa, FL 33612, USA

1 Rothman KJ, Michels KB, Baum M. For and Against: Declaration of Helsinki should be strengthened. $B M$ 2000;321:442-5. (12 August.)

2 Peto R. Trials: the next 50 years. BMJ 1998;317:1170-1.

3 Djulbegovic B, Lacevic M, Cantor A, Fields K, Bennett C,

Adams J, et al. The uncertainty principle and industrysponsored research. Lancet 2000;356:635-8.

4 Edwards SJL, Lilford RJ, Braunholtz DA, Jackson JC, Hewison J, Thornton J. Ethical issues in the design and conduc 1998;2:1-130.

5 Lilford RJ, Jackson J. Equipoise and the ethics of randomization.J R Soc Med 1995;88:552-9.

\section{All countries must have common standards for international research ethics}

Editor-The debate over changes to the Declaration of Helsinki is disappointing. ${ }^{1}$ It has in many ways muddied the waters instead of clearing the way to improving international research ethics standards.

What we see at the moment is a clear fault line between the American and British medical associations-both of which support lower standards of care for people living in developing countries-and continental European, Latin American, and some Asian medical associations, which reject such a double standard. In the United Kingdom the Wellcome Foundation is sponsoring a research project designed to bolster the case of the American and British medical associations but declined to sponsor a project critical of this campaign.

One of the crucial questions that have to be faced is: Do we want to see more clinical research undertaken whose primary objectives are solutions to economic rather than medical problems? If the answer is yes it is only logical to demand lower standards of care, because they are cheaper. If, on the other hand, we are serious about tackling the health problems of people in developing countries (this includes access to affordable drugs) surely we should question the economic frameworks that give rise to the purported necessity to develop cheaper drugs. Anglo-Saxon pragmatism, in this case, readily accepts the economic frameworks and tries to make the best out of the situation.

Is it unreasonable, then, to ask for a bit more honesty in the American and British campaign? These countries ought to state unequivocally that they think it ethically acceptable that people in developing countries die as a consequence of HIV infection acquired during preventive HIV vaccine trials. This is what the lower standards of care that both associations deem ethically acceptable will mean for the impoverished and otherwise vulnerable subjects in these trials. ${ }^{2}$ Reasons for this position can be found, but I find them unconvincing. A first step to improve the debate could surely be to be frank about what one does and doesn't consider acceptable with regard to, for instance, standards of care in preventive vaccine trials.

We should also be concerned about attempts to reach what will be called an international consensus on this matter. International research ethics meetings take place all over the world, but often scholars and treatment access activists based in developing countries can go only if they know a generous Western sponsor who pays for their airfare and accommodation. This itself renders these meetings unrepresentative.

Udo Schuklenk professor of bioethics University of the Witwatersrand, Faculty of Health Sciences, Parktown 2193, Johannesburg, South Africa

bioethic@chiron.wits.ac.za

1 Rothman KJ, Michels KB, Baum M. For and Against: Declaration of Helsinki should be strengthened. $B M$ 2000;321:442-5. (12 August.)

2 Schuklenk U, Ashcroft R. International research ethics Bioethics 2000;14:158-72.

\section{Authors' reply}

EDITOR-Lilford and Djulbegovic push the edge of the equipoise envelope by implying that patients rather than their doctors should be the ones who are in equipoise. This is a noble but perhaps impractical goal, because it requires more knowledge by patients than we can expect, even with improved communication. Even informing patients sufficiently for them to give meaningful consent has remained unsatisfactory. ${ }^{1}$ Meanwhile, the United States Food and Drug Administration does not recognise equipoise as an ethical requirement. ${ }^{2}$ ? We would be pleased with any mention of an equipoise requirement in the Declaration of Helsinki, be it of patients or doctors, on the individual or group level.

Defenders of local standards of care instead of a global standard for comparisons in medical experiments will undoubtedly be troubled by Schuklenk's incisive comment We believe, as he does, that global disparities in the standard of care only become hardened when inferior treatment is accepted as a treatment option in a medical experiment. His letter gives an interesting insight into the premise underlying the use of a local standard.

Kenneth J Rothman professor

Department of Epidemiology and Biostatistics, Boston University School of Public Health, Boston University Medical Center, Boston,

MA 02118-2526, USA

KRothman@bu.edu

Karin B Michels assistant professor

Harvard Medical School Obstetrics and

Gynecology Epidemiology Center, Brigham and

Women's Hospital, Boston, MA 02115, USA

1 Laforet GG. The fiction of informed consent JAMA 1976;235:1579-85

2 Temple R, Ellenberg SS. Placebo-controlled trials and active-control trials in the evaluation of new treatments. Part 1. Ethical and scientific issues. Ann Intern Med 2000;133:455-63.

3 Temple R, Ellenberg SS. Placebo-controlled trials and active-control trials in the evaluation of new treatments. Part 2: Practical issues and specific cases. Ann Intern Med 2000;133:464-70.

\section{Increased humanitarian deaths may not mean higher risks of dying}

EDITOR-Sheik et al fill an important gap in the literature on humanitarian assistance, where firm statistics are often unavailable. ${ }^{1}$ Their findings support the general opinion that more deaths have been occurring among humanitarian relief workers and that intentional violence has become an important cause of death. ${ }^{2}$ As the authors point out, however, the absence of denominators representing the populations at risk makes it difficult to determine if the actual risks of death have increased.

In a review of over 1550 deaths of United Nations peacekeepers no difference was found in crude death rates between the cold war years (1949-89) and the period immediately after the cold war (1990-8), despite a considerable increase in the total number of deaths observed. ${ }^{3}$ This increase was attributed primarily to a rise in the number and scale of UN peacekeeping commitments after the cold war. There was a 1.5 times greater risk of death from hostile acts after the cold war; risk factors included African missions, assertive peacekeeping operations, and missions involving humanitarian assistance. Unintentional violence remained the most common overall cause of death among peacekeepers, but the relative risk of unintentional violence has declined in the past decade.

The risks and circumstances of death may differ between humanitarian assistance and UN peacekeeping missions, but the rising numbers of deaths among relief workers can probably be explained by a surge in humanitarian activities since the cold war. For example, at the height of relief operations in Rwanda and Haiti there were more than 200 and 800 non-governmental organisations operating in the respective countries. ${ }^{4}$ At the same time, humanitarian missions are increasingly taking place under poor security conditions, with a lack of protection normally accorded under international humanitarian law. ${ }^{12}$ High staff turnover and recruitment problems have also led many non-governmental organisa- 
tions to employ young and inexperienced volunteers, who may face greater risks of exposure to danger. ${ }^{5}$

Greater accountability for the safety of humanitarian workers in the field is needed, and we must avoid the all too common and altruistic conclusion that "the humanitarian need must be greater than the risks involved."

Benjamin Seet deputy commander

Military Medicine Institute, Singapore Armed

Forces, Singapore 109680, Singapore

benseet@yahoo.com

1 Sheik M, Gutierrez MI, Bolton P, Spiegel P, Thieren M, Burnham G. Deaths among humanitarian workers. $B M$ J 2000;321:166-8. (15 July.)

2 Trintignac F, ed. A case by case analysis of recent crises: assessing 20 years of humanitarian action. Paris: Médecins du ing 20 years of

3 Seet B, Burnham G. Fatality trends in United Nations peacekeeping operations: 1948-1998. JAMA (in press)

4 Mackinlay J, ed. A guide to peace support operations. Providence RI, Thomas J Watson Jr Institute for International Studies, 1996.

5 Waldman R, Martone G. Public health and complex emergencies: new issues, new conditions. Am J Public Health 1999;89:1483-5.

\section{Costs and effectiveness of community postnatal support workers}

\section{Researchers must now focus on effectiveness with specific groups of women}

EDITOR-Evaluation of the effectiveness of home visiting programmes in the United Kingdom, as in Morrell et al's study, is much needed. ${ }^{1}$ Several systematic reviews of the effectiveness of these programmes have indicated that their success depends on the population selected, the extent to which the skills of the staff have been matched to the needs of the family, and the duration of the programme. ${ }^{2}$ The disappointing results of Morrell et al's trial might well be understood in terms of the first two of these factors in particular.

Perhaps most importantly, there is evidence of differential effects of home visiting programmes in subgroups of individuals. Several studies have shown that support of this nature that is offered to mothers who are already coping, or to mothers who are not experiencing adversity, can not only fail to produce positive outcomes but also lead to regression. ${ }^{3}$ One to one home visiting programmes have traditionally been used to provide intensive support to disadvantaged mothers and to women who have been identified as being at increased risk of poor outcomes. The use of a home visiting programme to provide support to mothers who are already coping must be questioned.

Just as importantly, little attention was given in the data analysis in Morrell et al's trial to the support workers being a source of variance as regards outcome. There is increasing recognition that the success of interventions of this nature depends on the capacity of the person providing the intervention to establish a trusting and respectful partnership with the mother. ${ }^{4}$
This suggests that the quality of the relationship between the mother and the support worker must be measured, and that the data must be analysed with the provider of the intervention (in this case, the support workers) being taken as an independent variable.

Further research is needed on the effectiveness of home visiting programmes. Morrell et al's trial will enable researchers to focus their attention on the effectiveness of such programmes with specific groups of postnatal women-for example, those at risk of poor parenting and abuse, whose needs may well be met by intensive programmes.

Jane Barlow primary care career scientist jane.barlow@dphpc.ox.ac.uk

Sarah Stewart-Brown director

Health Services Research Unit University of

Oxford, Institute of Health Sciences, Headington, Oxfordshire OX3 7LF

1 Morrell CJ, Spiby $\mathrm{H}$, Stewart P, Walters S, Morgan A. Costs and effectiveness of community postnatal support
workers: randomised controlled trial. BMJ 2000;321:593-8. workers: randomised controlled trial. BMJ 2000;321:593-8. (9 September.)

2 Cox AD. Preventing child abuse: a review of community based projects II: Issues arising from reviews and future directions. Child Abuse Review 1998;7:30-43.

3 Gough D. Child abuse interventions: a review of the research lit erature. London: HMSO, 1993.

4 Davis H, Spurr P. Parent counselling: an evaluation of community child mental health service. J Child Psychol Psychiatry 1998;39:365-76.

\section{Authors' reply}

Editor-Our trial was a pragmatic evaluation to assess the impact of a health technology provided in the natural setting, and to establish the effects on health of additional postnatal support provided in women's homes.

In the very early postnatal days (when our intervention took place) it is not always possible to distinguish mothers who appear to be coping from those who will go on to have difficulties. We did not think that we could predetermine a group of women at risk or the needs of their family at this stage, as defined either subjectively by professionals or by new mothers themselves.

Much of the literature on home visiting programmes comes from North America and is sufficiently different from our own for the results not to be transferable. Since many of those studies concentrated on particular subgroups of women regarded as at high risk, extrapolating results to groups with different needs would also be difficult.

Clearly it was important that the support workers had a trusting and respectfu partnership with the mothers. The women in our trial were very satisfied with their support worker and thought that the service was better than they had expected. It would be interesting to examine the impact of individual support workers as an independent variable, but we are not sure how valuable this might be in the context of service provision. Our study was not an explanatory trial, designed to tease out the efficacy of different components of postnatal support. Rather, it was a pragmatic trial of a new technology (support at home by postnatal support workers) compared with existing mainstream technology (routine postnatal care by midwives).
The skills of the support workers were standardised by the training they received, their ongoing supervision and mentoring, detailed activity records, and support meetings. Variation in the provision of support was largely at the request of individual women, since the service provided, within a clear role description, was intended to be woman centred.

The effectiveness of domiciliary visiting by health visitors in the United Kingdom has been scrutinised as part of other systematic reviews. We believe that further work should examine different models of provision of social support for women in the early postnatal period.

C Jane Morrell research fellow

Medical Care Research Unit, School of Health and Related Research (ScHARR), University of Sheffield, Sheffield S1 4DA

J.Morrell@sheffield.ac.uk

Helen Spiby senior lecturer

Mother and Infant Research Unit, University of Leeds, Leeds LS2 9LN

\section{Mental health services for people with learning disabilities}

\section{People with comorbidity can fall between two stools}

EDITOR-Hassiotis et al highlight many difficulties in providing services for people with mild learning disability and mental illness. ${ }^{1}$ Many such people fall between the two proverbial stools of general adult psychiatry and learning disabilities psychiatry. This is particularly so for people with mild learning disability and schizophrenia.

Individuals with mild learning disability are three times more likely than the general population to develop schizophrenia. ${ }^{2}$ Inpatient psychiatric care is required in many cases. Individuals unknown to a psychiatric service at the point of a first psychotic episode are, in the climate of closure of hospitals for people with learning disability, increasingly likely to be admitted to a general adult psychiatric ward. The effective management of a first episode of schizophrenia has attracted recent attention, ${ }^{3}$ but in the context of comorbid mild learning disability there are special considerations.

People with comorbidity may present complex management problems, many of which are not commonly seen in people with schizophrenia alone. Recent work has indicated that patients with comorbidity have fewer psychiatric admissions, for longer periods of time, than do patients with schizophrenia alone. ${ }^{4}$ They are also more likely to have a history of epilepsy, negative symptoms of schizophrenia, and impairment of episodic memory. ${ }^{4}$ A diagnosis of epilepsy may lead to difficulties with the treatment of schizophrenia, as most antipsychotic drugs (both typical and atypical) are epileptogenic. Negative symptoms are notoriously difficult to treat, and memory difficulties may contribute to poor adherence to treatment. 
At the point of discharge from hospital many of these patients require a high level of community support. This is not generally as a consequence of a record of contact with the police, a history of self harm, a history of misusing drugs or alcohol, or having additional psychiatric diagnoses. ${ }^{4} \mathrm{~A}$ proportion of patients with comorbidity originate from fragmented families with histories of learning disability or schizophrenia, or both, in family members and may have poor support networks. ${ }^{4}$

A recent case-controlled study of volumetric cerebral magnetic resonance imaging reported that, in terms of brain structure, patients with comorbidity more closely resemble those with schizophrenia than those with mild learning disability. ${ }^{5}$ In some cases, premorbid cognitive impairment may be associated with a severe and highly familial subtype of schizophrenia. ${ }^{45}$

Many contemporary studies of schizophrenia exclude people with premorbid mild learning disability; this may restrict our further understanding of the generality of this multifaceted condition.

Gillian Doody clinical senior lecturer in general psychiatry

University of Nottingham, Nottingham NG3 6AA Gillian.Doody@nottingham.ac.uk

1 Hassiotis A, Barron P, O'Hara J. Mental health services for people with learning disabilities. BMJ 2000;321:583-4. (9 September.)

2 Turner TH. Schizophrenia and mental handicap: an historical review, with implications for further research Psychol Med 1989;19:301-14

3 Frangou S, Byrne P. How to manage the first episode of schizophrenia. BMJ 2000;321:522-3. (2 September.)

4 Doody GA, Johnstone EC, Sanderson TL, Owens DGC, Muir WJ. 'Pfropfschizophrenie' revisited: schizophrenia in people with mild learning disability. $\mathrm{Br} J$ Psychiatr 1998; 173:145-53.

5 Sanderson TL, Best IJ, Doody GA, Cunningham Owen DG, Johnstone EC. The neuroanatomy of co-morbid G, John schizophrenia and learning disability-a controlled study.

\section{Medical needs are important too}

EDITOR-The editorial by Hassiotis et al highlights the need for competent and comprehensive mental health services for people with learning disabilities. ${ }^{1}$ From the paediatric perspective, however, the medical needs of this group are much wider and seem to be difficult to meet. The young adults for whom we have to find a suitable specialist medical input include those with severe epilepsy, often combined with a psychiatric disorder; those with cerebral palsy; those with severe autistic spectrum disorder; and those with complex neurological problems, which include cognitive impairment

Thus, if a learning disability is to be regarded as the province of psychiatry, people have to be trained to be able to manage this group of disorders or set up collaborative arrangements which include input from neurologists. When we are trying to define the medical needs of a group of people with one form of brain impairment-that is, cognitive-it is not surprising that this is found to coexist with several other major medical impairments. I do not believe that without such comprehensive input the mental health of disabled adults can be appropriately provided for.

Brian G R Neville professor of paediatric neurology Wolfson Centre, London WC1N 2AP

bneville@ich.ucl.ac.uk

1 Hassiotis A, Barron P, O'Hara J. Mental health services for people with learning disabilities. BMJ 2000;321:583-4. (9 September.)

\section{Differential diagnoses for asthma should include mediastinal masses}

EDITOR-The article by Payne et al emphasised the need to challenge the diagnosis of asthma in children whose symptoms of airways obstruction persist on treatment. The authors presented a table entitled "Diagnoses that may mimic or coexist with asthma." We have had many experiences of children with mediastinal masses who were initially diagnosed as having asthma, and we feel that airways obstruction due to malignancy should also be included in the differential diagnosis. The inclusion of mediastinal masses is important, although they are uncommon, since airways obstruction due to malignancy is not a stable condition and if unrecognised will go on to cause critical airways compression and respiratory arrest.

The crucial clinical sign in patients with airways obstruction due to malignancy is stridor rather than wheeze, and it is the difficulty in distinguishing between these that usually leads to delays in diagnosis. Other signs associated with mediastinal masses, such as cervical lymphadenopathy and superior vena cava obstruction, should be sought and if present must always arouse suspicion. The most important point, as stated by Payne et al, is that failure to respond to standard asthma treatment should lead to the diagnosis of asthma being challenged. This should, however, apply to both the initial response to bronchodilators and the longer term response to prophylactic medication. If there is doubt about the diagnosis of asthma then a chest radiograph will reveal any important mediastinal masses.

Andrew Peet specialist registrar acpeet@doctors.org.uk

Richard Grundy senior lecturer Bruce Morland consultant paediatric oncologist Michael Stevens consultant paediatric oncologist Birmingham Childrens Hospital, Steelhouse Lane, Birmingham B4 6NH

1 Payne DNR, Lincoln C, Bush A. Right sided aortic arch in children with persistent respiratory symptoms. $B M$ 2000;321:687-8. (16 September.)

\section{Improvement in prescribing can be measured only over time}

EDITOR-Avery et al say that practices with lower prescribing costs prescribe less, use cheaper items, and avoid new and expensive drugs. ${ }^{1}$ A five year old managing their pocket money could have told us the same basic economic statement. Without some look at clinical outcomes such studies are of little value. If in 10 years Avery et al could tell us that the low prescribers have just the same rate of coronary events, bypass grafts, suicides, osteoporotic hip fractures, and so forth as the high prescribers then they might have made a useful point. Currently, with more and more pressure from our paymasters to raise standards and follow clinical guidelines, some expensive prescribing is inevitable, unless we opt for therapeutic nihilism. That may simply shift the cost of our prescribing budgets into secondary care management. It is cheaper for us to avoid prescribing inhaled steroids, for example, when the cost of hospital admissions for status asthmaticus is borne by someone else, but it is hardly in our patients' best interests or ethical.

Like many general practitioners, I have over the years since prescribing analysis and cost (PACT) data came in tried to keep prescribing costs down by following good practice guidelines. Until the past 12 months my figures have always been below national and local averages, and during the past 20 years the average age at death for my male patients has risen from 70 years to 75 years and for women from 77 years to 83 years-perhaps an indication that I have done something right. But now, after the fiasco concerning generic drugs and with the increased use of drugs recommended in current clinical guidelines, our practice budget is well into negative balance, with a threat of reducing our services to balance the books. This, as you may imagine, is a source of considerable irritation, not helped by articles such as that by Avery et al, which contribute little to the debate, presumably take a lot of time and money, and are pretty pointless.

David F Bird general practitioner

French Weir Health Centre, Taunton, Somerset

TAI INW

dfbird@doctors.org.uk

1 Avery AJ, Rodgers S, Heron T, Crombie R, Whynes D, Pringle M, et al. A prescription for improvement? An observational study to identify how general practices vary observational study to identify how general practices vary in their growth in prescribing costs. [With

\section{Emphasis has shifted from medical ethics to bioethics}

EDITOR-Singer in his article on medical ethics has accurately compressed recent developments in medical ethics into a small space. 'Two important developments are, however, missing from his summary. Both have to do with a shift in emphasis from "medical ethics" to "bioethics," as the issues he identifies have moved from being internal concerns of the professions to matters of public, political debate.

The first is a growing emphasis on the process of bioethical decision making. Professionals and academics increasingly look for ways to resolve bioethical debates by involving members of the public in debates, not always successfully. Examples are the Oregon experiment in healthcare rationing and the consultation by the World Health Organization on the revisions of the Declaration of Helsinki. One might also 
consider the public inquiry of the Bristol Royal Infirmary in this light. Some interesting experiments have been made in public consultation that go beyond surveying or researching public attitudes-for example, the King's Fund's work on citizens' juries.

The second is the reincorporation of the language and jurisprudence of human rights into bioethics. Considering that much of contemporary bioethics started with the Nuremberg Code, it is interesting that human rights ideas have played a comparatively small part in professional and academic debates. With the inclusion of human rights law in British law, however, the influential role of the Council of Europe in bioethics policymaking, and the incorporation of human rights perspectives into world programmes (such as the United Nations' AIDS initiative, UNAIDS, and organisations involved in global health - such as the United Nations, the WHO, and the international medical charities), it is certain that human rights methods and ideas will play a powerful part in the development of bioethics ideas and policies. ${ }^{23}$

Both of these tendencies can be seen in what Singer surveys. I think that these issues will come to centre stage over the next 10 years, as they are already doing in debates over the new genetics and biotechnology. ${ }^{4}$

Richard E Ashcroft Sir Siegmund Warburg lecturer in medical ethics

Imperial College, London W2 1PG

r.ashcroft@ic.ac.uk

1 Singer PA. Medical ethics. BMJ 2000;321:282-5. (29 July.) Mann JD, Gruskin S, Grodin MA, Annas GJ. Health and human rights: a reader. London: Routledge, 1998.

3 Macklin R. Against relativism: cultural diversity and the search Macklin R. Against relativism: cultural diversity and the search for ethical universils
sity Press, 1999.

Bity Press, 1999. 4 Burley J, ed. The genetic revolutio

Oxford University Press, 1999

5 Chadwick R The Icelandic database: do modern times need modern sagas? BMJ 1999;319:441-4.

\section{Stapled haemorrhoidectomy offers substantial benefits}

EDITOR-Brisinda's synopsis of the contemporary treatment of haemorrhoids was timely and comprehensive. ${ }^{1}$ We have recently undertaken a detailed questionnaire survey of all 800 general and colorectal specialist surgeons in the United Kingdom and Ireland; with the exception of a few specific treatments, such as the injection of botulinum toxin for sphincter spasm, all the treatment modalities mentioned are currently used with varying degrees of popularity. ${ }^{2}$

We strongly support the comments made regarding the role of stapled "haemorrhoidectomy" in the surgical management of prolapsing haemorrhoids. Our own experience of this operation (currently over 80 performed) confirms that this procedure is effective in reducing postoperative pain (thus facilitating day case surgery) and leads to a rapid return to normal activities compared with the conventional excisionligation (Milligan-Morgan) procedure. ${ }^{3}$ As with any innovative surgical technique, however, concerns will inevitably be raised about issues of safety and efficacy. ${ }^{4}$
Although stapled haemorrhoidectomy does increase operative costs, total hospital costs may be reduced as a consequence of decreased bed usage. The comment that the stapled procedure does not allow for the treatment of concomitant anal disease was a little unclear. We presume this refers to the external haemorrhoidal component, such as oedematous anal skin tags. In his original description of the technique Longo hypothesises that, by interrupting the feeding haemorrhoidal vessels in the resectionanastomosis, the skin tags will regress in the postoperative period, eventually forming radial cutaneous folds. ${ }^{5}$ This has been confirmed by our own series, in which more than 50 patients have been followed up for six months postoperatively. We regard excision of any external component as unnecessary, especially if such excision is likely to be a major factor contributing to postoperative pain.

We would also echo Brisinda's comments that the stapling procedure requires advanced surgical skills and should be carried out only by operators with sufficient technical experience. Surgeons should be familiar with operating high in the anorectum and undergo specific training, factors that may be important in the small numbers of adverse events which have been reported in relation to this procedure. ${ }^{4}$ In the hands of appropriately trained surgeons stapling offers substantial benefits in the surgical management of haemorrhoids

Garth C Beattie specialist registrar in general surgery Daisy Hill Hospital, Newry, County Down BT35 8DR

Malcolm A Loudon consultant colorectal surgeon Victoria Hospital Kirkcaldy, Fife KY2 5AH malcolml@cwcom.net

1 Brisinda G. How to treat haemorrhoids. BMJ 2000:321:582-3. (9 September.)

2 Beattie GC, Loudon MA, Wilson RG. Contemporary management of haemorrhoids. Colorectal Dis 2000;2:17

3 Beattie GC, Lam JPH, Loudon MA. A prospective evaluation of the introduction of circumferential stapled anoplasty in the management of haemorrhoids and mucosal prolapse. Colorectal Dis 2000;2:137-42.

4 Cheetham MJ, Mortenson NJ McC, Nystrom P-O, Kamm MA, Phillips KS. Persistent pain and faecal urgency after stapled haemorrhoidectomy. Lancet 2000;356:730-3.

5 Longo A. Treatment of haemorrhoidal disease by reduction of mucosa and haemorrhoidal prolapse with a circular suturing device: a new procedure. In: Procedings of the 6th World Congress of Endoscopic Surgery and 6 th the 6in Whoscopic Surgery and 6t International Congress of European Association for Endoscopic
Surgery. Rome, 3-6 June 1998:777-84.

\section{Using death certificates to identify malpractice might be difficult}

EDIToR-In January 2000 Dr Harold Shipman, a general practitioner in Greater Manchester, was convicted of murdering 15 of his patients. ${ }^{12}$ This conviction has fostered considerable comment and a need to prevent any recurrence. Although a quantitative technique to identify malpractice has limitations," a description of basic data should act as a starting point.

We performed some simple investigations on death certificate records for 1998 , after agreement from the general practice subcommittee. Our comments highlight some difficulties associated with the investigation of death certificates from an electronic record.

The first problem concerned technical issues with the dataset. These included identification of a general practitioner, as opposed to a hospital consultant; electronic sorting was difficult because many fields (including general practitioners' names, initials, and addresses) were inconsistent. In 30 of our 6000 records the address of the patient rather than the general practitioner was recorded, and general practitioners have satellite surgeries, which legitimately adds a second address permutation.

The second problem was that difficulties in identifying general practitioners in the Grampian register were confounded by out of hours cover, trainees, and locum cover from outside Grampian. One particular problem arose when we seemed to identify a general practitioner who signed 30 death certificates; it transpired that two general practitioners have identical surnames and initials and are both based in the same area. Including the doctor's registration number on the death certificate would yield a useful additional field.

The average (SD) number of certificates signed by general practitioners grouped into practices was 27.65 (19.87) (range 1-92). The median was 22 . The average number for an individual general practitioner was 5.85 (4.47) (range 1-24; median 11).

Grampian has some 93 general practices; 88 appeared in this analysis. Inspection of the data raised many questions-for example, where do individuals die (city versus rural); do individuals get appropriate choice?-and issues concerning workloads and staffing levels.

The trust cannot escape its corporate responsibility and, specifically, its need to show clinical governance. To this end a multidisciplinary group has been set up to establish a mechanism for judging the quality of an individual's death.

Adam Coldwells development and research manager Fiona Fraser clinical audit assistant

Pam Tavendale trust-wide clinical governance coordinator

Grampian Primary Care NHS Trust, Aberdeen AB25 2ZP

adam.coldwells@ghc.grampian.scot.nhs

George Crooks associate medical director

Gordon Peterkin medical director

Grampian Primary Care NHS Trust, Royal Cornhill Hospital, Aberdeen AB25 2ZH

1 O'Neill B. Doctor as murderer. BMJ 2000;320:329-30. 2 Dyer C. Tighter control on GPs to follow doctor's murder convictions. BMJ 2000;320:331.

3 Frankel S, Sterne J, Smith G. Mortality variations as a measure of general practitioner performance: implications of the Shipman case. BMJ 2000;320:489.

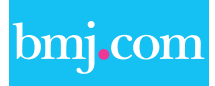

Rapid responses

Correspondence submitted electronically

is available on our website 